Reference

[1] Sheila Oates Macdonald, "Locally finite varieties of groups arising from Cross varieties", Buzl. Austral. Math. Soc. 4 (1971), $211-215$.

University of Queensland,

St Lucia,

Queensland.

BULL. AUSTRAL. MATH. SOC.

MOS 22A15, 20M20

VOL. $4(197 \mid), 432$.

(54H99)

\title{
A remark on compact semigroups having certain decomposition spaces embeddable in the plane: Corrigendum
}

\section{R.P. Hunter and L.W. Anderson}

Through an editorial error, the second sentence in the penultimate paragraph of [1] does not make sense. The first line in that paragraph should read:

"It now follows that $K / G$ separates the plane, where $K$ is, as usual," .

Reference

[1] R.P. Hunter and L.W. Anderson, "A remark on compact semigroups having certain decomposition spaces embeddable in the plane", BulZ. Austraz. Math. Soc. 4 (1971), 137-139.

Editor's note, dated 25 January 1971. 